Cuadernos de Filología Clásica. Estudios Latinos

ISSN: 1131-9062

http://dx.doi.org/10.5209/CFCL.56189

\title{
El ejemplar salmantino de los Aphthonii clarissimi rhetoris Progymnasmata Ioanne Maria Catanaeo interprete, de Juan Lorenzo Palmireno (BG/221825): la recuperación de una obra perdida ${ }^{1}$
}

\author{
Trinidad Arcos Pereira ${ }^{2}$
}

Recibido: 13 de junio de 2016 / Aceptado: 1 de febrero de 2017

Resumen. Juan Lorenzo Palmireno publica en 1552 en Valencia su Aphthonii Clarissimi Rhetoris Progymnasmata, con la versión de Joannes Maria Cataneo, obra de la que hasta ahora no conservábamos ejemplares. El trabajo presenta el ejemplar de esta obra que se conserva en la Biblioteca Universitaria de Salamanca con la signatura BG/221825 (8) y que he hallado en 2014 durante el transcurso de un trabajo sobre los Progymnasmata. Está encuadernado con ocho obras más y procede del Colegio Mayor de Cuenca. La obra se inicia con una epístola dedicatoria a Jerónima Ribot y Ribelles, señora de Alcudia y Rassalany ( $1 \mathrm{v}-2 \mathrm{v})$, fechada en Valencia, el 23 de septiembre de 1522. A continuación, aparece la traducción de Giovanni Maria Catanaeo de los Progymnasmata de Aftonio (3r-22v), que ocupa la mayor parte del libro (Aphtonii Rhetoris Progymnasmata, Ioanne Maria Catanaeo interprete) y que el humanista alcañizano ha preferido a las de Agrícola, Bonfini y Prisciano (sic). Le siguen los Ioannis Laurentii Palmyreni Scholia in Aphthonium (23r-26v), a los que precede una carta al lector en la que Palmireno explica la naturaleza de su comentario y las diferencias con otros. El volumen se cierra con una carta del librero Antoni Sanahuja (Antonius Sanahuia Bibliopola studioso, 28r-28v).

Palabras clave: Juan Lorenzo Palmireno; Aftonio; progymnasmata.

[en] The copy of Aphthonii clarissimi rhetoris Progymnasmata Ioanne Maria Catanaeo interprete from Salamanca (BG/221825) written by Juan Lorenzo Palmireno: the recovery of a lost work

\footnotetext{
Abstract. In 1552, Juan Lorenzo Palmireno publishes in Valencia his Aphthonii Clarissimi Rhetoris Progymnasmata, together with Joannes Maria Catanaeus' version, however no surviving copy is known to exist so far. The aim of this work is to present the copy I have found in 2014 at the University Library of Salamanca, BG/221825 (8). The text is bound with other eight works and comes from the Colegio Mayor of Cuenca. It begins with a dedicatory epistle to Jerónima Ribot y Ribelles, «señora de Alcudia y Rassalany» (1v-2v), dated 23 September 1522. Afterwards, we find Joannes Maria Catanaeus' translation of Aphtonius' Progymnasmata, which takes up most of the book (Aphtonii Rhetoris Progymnasmata, Ioanne Maria Catanaeo interprete); it is worthy to note that the humanist from Alcañiz preferred this translation to the ones by Agricola, Bonfini and Prisciano (sic). Following the translation, we find the Ioannis Laurentii Palmyreni Scholia in Aphthonium (23r-26v), which are preceded by a letter to the reader in which Palmireno explains the nature of his commentary and its distinctive features in com-

1 Este trabajo se ha realizado en el marco del Proyecto de Investigación FFI2014-53859-P, financiado por el MINECO.

2 Universidad de las Palmas de Gran Canaria.

e-mail: trinidad.arcospereira@ulpgc.es
} 
parison with other ones. The volume ends with a letter by the bookseller Antoni Sanahuja (Antonius Sanahuia Bibliopola studioso, 28r-28v).

Keywords: Juan Lorenzo Palmireno; Aphthonius; progymnasmata.

Sumario. 1. Introducción. 2. Descripción. 3. Epístola dedicatoria. 4. La versión de Joannes Maria Catanaeus. 5. Carta de Palmireno al lector. 6. Los Ioannis Laurentii Palmyreni Scholia in Aphthonium. 7. Quomodo status cognoscemus secundum Hermogenem. 8. Carta de Antoni Sanahuja al estudioso. 9. Conclusiones. 10. Referencias bibliográficas.

Cómo citar: Arcos Pereira, T., «El ejemplar salmantino de los Aphthonii clarissimi rhetoris Progymnasmata Ioanne Maria Catanaeo interprete, de Juan Lorenzo Palmireno (BG/221825): la recuperación de una obra perdida», Cuad. Filol. Clásc. Estud. Lat. 37.1 (2017), 105-118.

\section{Introducción}

En 1552, Juan Lorenzo Palmireno ${ }^{3}$, mientras desempeña la Cátedra de Poesía en el Estudi General de Valencia, publica en las prensas de Joannes Mey de esta ciudad su Aphthonii Clarissimi Rhetoris Progymnasmata, con la versión de Joannes Maria Cataneo. Hasta ahora, los estudiosos de Palmireno han considerado que esta obra estaba perdida. Así lo señala de la Vega, cuando indica que el único ejemplar estaba depositado en la biblioteca del Palacio Episcopal de Teruel, pero que se desconoce su paradero actual (1973, 6, n. 7); esta información es recogida por Gallego Barnés en su estudio sobre Palmireno $(1982,49)$ y la vuelve a reiterar en publicaciones posteriores $(2002,165$, n. 25; y en el 'Prólogo' a Cea, 2009); también se hace eco de la pérdida del ejemplar Luján en su tesis doctoral $(1997,19)$, siguiendo a Gallego, así como Pérez Custodio, que afirmaba que no se había localizado todavía ${ }^{4}$ (2002, 245-246; 2003, LVI-LVII).

La obra no está recogida en el catálogo de Green-Murphy (2006) en la entrada de Aphthonius, ni en la de Catanaeus ni en la de Palmireno. Tampoco la incluye Bonmatí $(2006,138)$ en la relación de obras de Palmireno.

\section{Descripción}

El objetivo de este trabajo es presentar el ejemplar de los Aphthonii Clarissimi Rhetoris Progymnasmata de Palmireno que he localizado en la Biblioteca Universitaria de Salamanca ${ }^{5}$, con la signatura BG/21825 (8). Está encuadernado con otras ocho obras en un volumen misceláneo en $8^{\circ}$, que procede del Colegio Mayor de Cuenca ${ }^{6}$. En el lomo aparece Varia opuscula pueris Paedagogica ${ }^{7}$ y presenta el siguiente contenido:

3 Sobre la vida y obra de Juan Lorenzo Palmireno son fundamentales los trabajos de Gallego (1982) y Maestre (1990, 127-227).

4 Una vez enviado el artículo para su publicación, durante el VIII Congreso de la Sociedad Española de Estudios Latinos, la profesora Violeta Pérez Custodio presentó el hallazgo de otro ejemplar de esta obra en la Biblioteca Nacional de Portugal, encuadernado también en un volumen facticio (RES.682/1), y cuyo estudio ha publicado en el número de 2016 de Euphrosyne.

5 Localicé la obra en 2014 cuando realizaba un trabajo sobre los Progymnasmata para el proyecto de Investigación FFI2014-53859-P, financiado por el MINECO.

6 En 1500 funda el Colegio Mayor de Santiago el Zebedeo Diego Ramírez de Villaescusa, obispo de Cuenca, por lo que se le conoce como Colegio Mayor de Cuenca. En 1523 el papa Adriano VI le concede la bula de aprobación y confirmación con los mismos derechos que el de San Bartolomé de Salamanca y los de Santa Cruz y San Gregorio de Valladolid (Carabias 1983, 57-59).

7 En la descripción catalográfica respeto la grafía 'u/v' que aparece en los textos. 
(1) Marci Tullii Ciceronis Orpheus siue de Adolescente studioso, ad Marcum filium Athenas. Nuper inuentus, \& in lucem editus. Venetiis, apud Io. Baptistam Ciottum, typographum, \& bibliopolam Academiae Venetae, 1594 (signatura antigua b15552901).

(2) [Kyrou Theodorou Prodromou tou en Kotyaioi tes Phrygias episkopou Poiemata] = Cyri Theodori Prodromi Cotyaei Phrygiae episcopi Poemata cum versione Latina, argumentis \& notis Hieremiae Erardi M. Lipsiae, impensis Voegelinianis, 1598 (Lipsiae, excudebat Michael Lantzenberger, 1598) (signatura antigua b15555474).

(3) Cornelius Nepos De viris illustribus. Lugduni, sub scuto Coloniensi, apud Ioannem \& Franciscum Frellonios, fratres, 1543 (signatura antigua b15554612).

(4) Querela pacis: undique gentium eiectae profligataeque autore Des[iderio] Erasmo Rot[erodamo]. Lug[duni], Seb[astianus] Gryphius Germ. excud[ebat], 1529 (signatura antigua b1555479).

(5) Vita Luciani ex Suida. Literarum profanarum studium, nec impium, nec inutile esse Christianis adolescentibus, Sinapio Autore ad D. Ioan. Locerum Medicum. Haganoae, per Ioan. Secerium, $1528^{8}$ (signatura antigua b15555707).

(6) Magni Basilei opusculum morale Ad pueros ex Leonardi Aretini uiri eloquentissimi translatione latinum redditum; cui appositae sunt perutiles adnotationes Fredenandi Pinciani uiri eruditissimi ad Graecam ueritatem restitutae. Accesserunt insuper Alexij Venegas in eumdem Basileum quaedam non contemnenda scholia, Alphonso Cedillio praeceptori suo, musaeique Toletani moderatori celebratissimo nuncupata. Toleti, Ioannes ab Ayala typographus excudebat, 1544, postridie Epiphanie Virginei partis (signatura antigua b15556451).

(7) M.T.C. Oratio pro Archia poeta Doctorum uirorum scholiis Adiectis quibusdam Francisci Cervantis Sanazari elucidationibus illustrata. Excudebat Hispali Dominicus de Robertis, 1544 (signatura antigua b1555742).

(8) Aphthonii clarissimi rhetoris Progymnasmata Ioanne Maria Catanaeo interprete, nunc denuo recognita iuxta veritatem Graeci exemplaris \& scholijs illustrata per Ioannem Laurentium Palmyrenum Alcanizensem ludimagistrum Valentinum D. Hieronymae Ribotae dicata. Accessit etiam ex Hermogenis sententia, quo modo status causae cognosci debeat. Valentiae, ex officina Ioannis Mey Flandri, prostant exemplaria apud Antonium Sanahuiam, sub scuto Beatae Mariae \& D. Antonij, 1552 (signatura antigua b15548193).

(9) Iul. Alexandrini medici, Archiatri Caesarei, Paedotrophia siue de puerorum educatione liber. Tiguri, Apud Christophorum Froschouerum, 1559 (signatura antigua b15557637).

Estas obras formaban parte de los opuscula que acompañaban al M.T. Ciceronis De partitione oratoria dialogus: uno fasce, quod aiunt, omnem dicendi doctrinam complectens una cum scholijs Christophori Hegendorphini, iam recens \& natis \& editis. Et alia quaedam opuscula graeca elegantissima ab eodem Hegendorphino latine reddita, quorum titulos in proxima pagella lector reperies. Haganoae, per Ioan. Secerium, 1528, como puede comprobarse en el ejemplar fotocopiado de una microficha de la Bibliothek der Universität de Friburgo que tiene la Biblioteca salmantina con la signatura BG/114631. Sin embargo, en el ejemplar salmantino faltan varios cuadernillos y solo contiene Vita Luciani ex Suida y Literarum profanarum studium, nec impium, nec inutile esse Christianis adolescentibus. Sinapio Autore ad D. Ioan. Locerum Medicum. 
El ejemplar salmantino de la obra de Palmireno consta de 28 folios en $8^{\circ}$, se encuentra en buen estado de conservación y se lee sin dificultad. Su título refleja el contenido de la obra, como ya había recogido Domingo Gascón y Guimbao en sus notas (Gallego 1982, 49):

Aphthonii clarissimi rhetoris Progymnasmata Ioanne Maria Catanaeo interprete; nunc denuo recognita iuxta veritatem Graeci exemplaris \& scholijs illustrata per Ioannem Laurentium Palmyrenum Alcanizensem ludimagistrum Valentinum D. Hieronymae Ribotae dicata. Accessit etiam ex Hermogenis sententia, quo modo status causae cognosci debeat.

Comienza con la carta dedicatoria a Jerónima Ribot y Ribelles, señora de Alcudia y Rassalany (1v-2v), fechada en Valencia, el 23 de septiembre de 1522. A continuación aparece la traducción de Giovanni Maria Catanaeo de los Progymnasmata de Aftonio, que ocupa la mayor parte del libro: Aphtonii Rhetoris Progymnasmata, Ioanne Maria Catanaeo interprete:

Fabula (3r-3v), Narratio (3v-4r), Chria (4r-5r), Sententia (5r-6r), Confutatio (6r$7 \mathrm{v})$, Confirmatio (7v-9r), Locus Communis (9r-10v), Laudatio (10v-13r), Vituperatio (13r-14v), Comparatio (14v-15v), Ethopoeia (15v-16v), Descriptio (16v18v), Causae (18v-20v), Promulgatio Legis (20v-22v).

Siguen los Ioannis Laurentii Palmyreni Scholia in Aphthonium (23r-26v), que están precedidos por una carta al lector en la que el propio autor explica la naturaleza de su comentario y las diferencias con otros; posiblemente se refiera al de Lorich que ya circulaba en numerosas versiones por toda Europa ${ }^{9}$.

El volumen se cierra con un resumen sobre el reconocimiento de los distintos status de Hermógenes (Quomodo Status cognoscemus secundum Hermogenem, 27r-28r) y con una carta del librero Antoni Sanahuja ${ }^{10}$ (Antonius Sanahuia Bibliopola studioso, 28r-28v).

El interés de Palmireno por la obra de Aftonio se remonta a su adolescencia, cuando estudiaba en Alcañiz. Sus maestros aconsejan a su padre que no lo envíe a la escuela porque no saca provecho de ella. Sin embargo, estos problemas de aprendizaje parecen más responsabilidad del método seguido en las aulas alcañizanas que de la inteligencia del humanista, como señala él mismo en El estudioso cortesano (1573, 30):

Conoscia mi ingenio tan atapado que pensaua nunca salir con disciplina alguna. Tanto que siendo moçuelo mi maestro dixo a mi padre: "Este mochacho nunca

9 El amplísimo comentario de Lorich a la traducción partim Agricola, partim Catanaeo se había publicado por primera vez en 1542 y, años más tarde, en 1546 se edita en Frankfurt una nueva edición que en la época en la que sale a la luz el tratado de Palmireno ya se había convertido en un éxito editorial. Véase Johnson (1942-43), Clark (1952), Margolin (1979), Green-Murphy (2006), Cuyás (2014), Arcos-Cuyás (2014).

10 Antoni Sanahuja fue un importante editor, impresor y librero que desarrolló su actividad en Valencia en la segunda mitad del siglo XVI (1552-1564). Durante los primeros años desarrolla su labor como editor y librero que imprime en las prensas de Joan Mey sus primeros libros entre los que se encuentra esta obra de Palmireno. En 1554, Sanahuja establece su propia imprenta independiente de la de Mey en la que publica obras religiosas y humanísticas en latín, castellano y catalán. En 1564, su nombre deja de aparecer en el pie de imprenta. Noticias sobre él y una relación de las obras editadas e impresas por Sanahuja pueden consultarse en Moll (2011). 
habla, sacadlo del estudio. No quise yo salir y estuue siempre mudo en Grammatica. Alcance un librico de Ratione studii de Erasmo, alabaua me alli Aphthonii progymnasmata, busquelo, estuue me con el quatro meses exercitando solo en Cañada uellida, aldea tan sola que en toda la semana hauia con quien hablar, pero mi necessidad me hizo despertar, que despues que me huue exercitado en Chrias, narrationes, locos communes y Theses, los que me conoscian poco antes tan mudo, creyan que todo lo que hablaua dezia decorado.

\section{Epístola dedicatoria}

Como ya hemos dicho antes, la obra está dedicada a Jerónima de Ribot y Ribelles, hija de Tomás Jerónimo Ribot, señor de Godella y Rocafort, casada con Acasi de Montagut y Ribelles, hijo de Joan de Montagut, que cederá post suam mortem a los nuevos esposos la baronía de Alcudia, uno de los centros más importantes de producción y manufactura de la seda en el Júcar (Vallés 2002, 102-103; Garés 2013,716). Muere en 1559.

Jerónima de Ribot fue discípula de Palmireno, como él mismo señalaba en el $R a$ zonamiento $(1573,185)$ : «Bien conocieron uuestras Mercedes mi discípula, a quien yo dediqué mis Comentarios sobre Apthonio, siendo casada y la mas hermosa desta ciudad, y de veynte y cinco años».

La carta muestra la estrecha relación entre maestro y discípula puesto que señala que, desde que se ha marchado Jerónima a Alcudia, se ha interrumpido la correspondencia entre ambos y se queja de que no ha recibido cartas suyas ni en latín ni en lengua vulgar, como antes solía suceder, de modo que sospecha que se han perdido por los conflictos bélicos o que las han interceptado. Por ese motivo, para no tener que confiar en ningún intermediario, le envía la obra de Aftonio para reanudar la correspondencia entre ambos y como testigo público de su respeto y gratitud.

De la misma manera que Juan Andrés Estrany ${ }^{11}$ dedica su Lactancio a Ángela Mercader-Sábata, así Palmireno dedica su Aftonio a Jerónima de Ribot, igualándolas. Ángela Mercader-Sábata y Boil, señora de Argeleta, era hija de Pedro Mercader y Sábata. Según Escolano, en sus Décadas (libro 7, 719), estudió latín, filosofía y teología, y su fama era tan grande que Vives la elogia en su De institutione foeminae christianae como ejemplo de mujer que aúna inteligencia e ingenio con honestidad y la compara con las hijas de Tomás Moro. Poseyó una gran biblioteca en su casa en Valencia que fue centro de reunión de un círculo literario de profesores y poetas como menciona Vives en el diálogo 22 de su Linguae exercitatio (Durán 2002, 2450, n. 10; 2003).

Palmireno llama a Jerónima mecoenas optima et hera nobilissima, utriusque linguae peritissima y discipula utraque lingua exercitatissima, y tiene en tan alta consideración su opinión que afirma que a Aftonio, aprobado por todos los hombres,

11 Juan Andrés Estrany, discípulo de Nebrija en Alcalá, estudiante en París, amigo de Vives, fue rector del Estudi General de Valencia en 1518 y en 1521 (Durán en Anyés 2001, 13-14). Conocemos sus obras por los testimonios de sus contemporáneos, pero no ha llegado ninguna hasta nosotros. Entre ellas se menciona un volumen que contiene las Annotationes in libros IV Dialogorum B. Gregorii PP. Annotationes in Homiliam eiusdem super Ezechielem. In Lactantii Firmiani Libros VII Diuinarum Institutionum, Annotationes in librum unum Lactantii, de ira Dei. Et in librum unicum eiusdem de Opificio Dei, al que posiblemente se refiera Palmireno (Díaz 2003, vol. VII, 377). 
solo le falta la aprobación de una mujer, la de ella (A2r). En la epístola, el humanista presenta su obra y afirma que ha confrontado las versiones de Agrícola, Cataneo, Bonfini y Prisciano (sic) con el códice griego y ha añadido breves comentarios (scholiola laconica).

Asimismo, pide a su mecenas que no menosprecie este libellus como exiguus et angustus porque, como Ctesibio y Arquímedes movieron con pequeños instrumentos moles inmensas, Aftonio con estos catorce ejercicios menores nos ha proporcionado los oradores más grandes y para respaldar esta afirmación de la utilidad de los ejercicios remite a Quintiliano. Finalmente, añade que, si ella aprueba esta obra, publicará su comentario a los Colloquia de Vives y otros que mantiene guardados.

\section{La versión de Joannes Maria Catanaeus}

En cuanto a la elección de la versión de los progymnasmata, el humanista, como hemos visto en la carta dedicatoria, afirma que ha cotejado las traducciones de Agrícola, Bonfini, Prisciano y Cataneo con el códice griego y que ha aportado su propio juicio. Pese a su afirmación, la traducción que nos ofrece es solo la de Cataneo sin variantes significativas. De las versiones de Cataneo ${ }^{12}$, Palmireno se sirve de la publicada junto a otras obras retóricas en 1521 por Johann Froben en Basilea con el apoyo de Beato Renano ${ }^{13}$. Las lecturas diferentes que hemos encontrado consisten en corrección de errores, cambio de formas verbales, errores y lecturas propias. Como muestra podemos señalar las siguientes:

\begin{tabular}{|c|c|c|}
\hline \multicolumn{3}{|c|}{ Corrección de errores } \\
\hline Progymnasma & Edición de Froben & Ejemplar de Palmireno \\
\hline Narratio & $\begin{array}{c}\text { decorem (p. 192) } \\
\text { indiferens (p. 193) }\end{array}$ & $\begin{array}{c}\text { decorum (f. 3v) } \\
\text { differens (f. 3v) }\end{array}$ \\
\hline Sententia & decoris (p. 197) & dedecoris (f. 5v) \\
\hline Confutatio & poeticae (p. 198) & poetae (f. 6v) \\
\hline Locus communis & qua (p. 204) & quo (f. 9v) \\
\hline Comparatio & $\begin{array}{c}\text { delegit } \text { (p. 216) } \\
\text { pleraque multa (p. 217) }\end{array}$ & $\begin{array}{c}\text { pluraque multo (f. 15r) } \\
\text { hanc sanctionem (f. 21r) } \\
\text { subiacent (f. 21v) }\end{array}$ \\
\hline Promulgatio legis & hoc sanctionem (p. 228) \\
subiacet (p. 230)
\end{tabular}

12 En el cotejo de las traducciones de Cataneo que se habían publicado antes de la obra de Palmireno, hemos advertido que es posible establecer dos versiones con variantes significativas entre ellas. Próximamente aparecerá publicado el estudio de estas variantes en RELat (2017).

13 Beato Renano, humanista alemán, trabajó con Froben en la edición de textos entre los que se encuentra el volumen en el que está incluida la traducción de Cataneo. Este contiene la edición de obras retóricas como Rutilii Lupi de figuris sententiarum et locutionis libri II, Rhomani Aquilae de nominibus figurarum et exemplis libri I, Iulii Rufiniani de figuris sententiarum et elocutionis libri I, Sulpitii Victoris oratoriarum institutionum praecepta ad. M. Silonem... De la contribución de Beato Renano a la edición señala el impresor en su Epistola ad lectorem: Quod si quid hinc capies commodi lector totum uelim illud Dn. Beato Rhenano acceptum feras. Qui hunc codicem ex Spirensi bibliotheca obliteratum alioqui, uelut ab inferis in uitam reduxit.Tuum erit candide lector quicquid est nostrae industriae boni consulere (Veterum...,1521, Ioannis Frobenii ad lectorem epistola, p. 4). 


\begin{tabular}{|c|c|c|}
\hline \multicolumn{3}{|c|}{ Errores } \\
\hline Progymnasma & Edición de Froben & Ejemplar de Palmireno \\
\hline Confutatio & amore (p. 199) & amare (f. 7r) \\
\hline Confirmatio & Ladone (p. 201) & Lodone (f. 8r) \\
\hline Locus communis & actionis (p. 203) & actionibus (f. 9r) \\
\hline Laudatio & sapiente (p. 211) & sapientiae (f. 13r) \\
\hline Thesis & $\begin{array}{c}\text { consideratio non habet personam } \\
\text { (p. 223) }\end{array}$ & $\begin{array}{c}\text { consideratio est non habens } \\
\text { personam (f. 18v) } \\
\text { personas (f. 18v) }\end{array}$ \\
& filios morte priuatur (p. 227) & filios matur (f. 20r) \\
\hline Promulgatio legis & dices (p. 229) $21 \mathrm{v})$ \\
\hline
\end{tabular}

\begin{tabular}{|c|c|c|}
\hline \multicolumn{3}{|c|}{ Cambio de formas verbales, tiempos y modos } \\
\hline Progymnasma & Edición de Froben & Ejemplar de Palmireno \\
\hline Confirmatio & $\begin{array}{c}\text { utentur (p. 201) } \\
\text { prospiciet (p. 203) }\end{array}$ & $\begin{array}{c}\text { utantur (f. 7v) } \\
\text { prospicit (f. 8v) }\end{array}$ \\
\hline Descriptio & $\begin{array}{l}\text { fecit (p. 220) } \\
\text { licet (p. 221) }\end{array}$ & $\begin{array}{c}\text { facit (f. 17r) } \\
\text { licebit (f. 17v) }\end{array}$ \\
\hline Thesis & reddiderint (p. 226) & reddant (f. 20r) \\
\hline
\end{tabular}

\begin{tabular}{|c|c|c|}
\hline \multicolumn{3}{|c|}{ Variantes propias } \\
\hline Progymnasma & Edición de Froben & Ejemplar de Palmireno \\
\hline Sententia & quorum (p. 196) & quales ii quorum (f. 5r) \\
\hline Confirmatio & num (p. 201) & nonne (f. 8r) \\
\hline Laudatio & fortunasque patieris (p. 207) & formasque partieris (f. 11v) \\
\hline Thesis & quoniam (p. 225) & licet (f. 19v) \\
\hline Promulgatio legis & $\begin{array}{c}\text { omnes igitur (p. 229) } \\
\text { examinaturos esse (p. 229) }\end{array}$ & $\begin{array}{c}\text { omnes praeterea (f. 21r) } \\
\text { examinaturi esse (f. 21r) }\end{array}$ \\
\hline
\end{tabular}

\section{Carta de Palmireno al lector}

En la carta al lector que precede a los Scholia in Aphthonium Palmireno justifica la brevedad del comentario con una cita de Quintiliano sin mencionarlo (QviNT. inst.8.5.30), non potest esse delectus, ubi de numero laboratur: «no puede existir selección cuando lo que importa es la cantidad». Mientras que otros tienen comentarios prolijos, su intención es diferente, pues, siguiendo a Teón (prog.70), que aconseja extraer ejemplos de los autores antiguos apropiados para cada ejercicio, él los ofrece para facilitar el trabajo de los maestros, pero solo indicando 
las fuentes. Señala que para lo demás se puede recurrir a la confrontación con las cuatro traducciones insignes de Aftonio: las de Agrícola, Prisciano (sic), Bonfini y Cataneo, y añade que no es necesario mostrar la utilidad de los ejercicios puesto que Quintiliano ya lo hizo al afirmar que son necesarios para el que pretende ser orador. Finaliza la carta con la asignación de los ejercicios a los tria genera: fabula, narratio, chria, sententia y thesis al deliberativo; confutatio, confirmatio y locus communis al judicial; y laus, uituperatio, imitatio y comparatio al demostrativo. Sin embargo, en el apartado dedicado al reconocimiento de los status de Hermógenes, se ofrece otra distribución: fabula y narratio se pueden utilizar en los tres géneros, chria y confirmatio en el judicial y en el deliberativo, en el laudatiuum se mira el linaje, la vida y otros elementos que ya ha mencionado antes y lo mismo sucede con la uituperatio, la comparatio en el demostrativo y judicial, la ethopoeia en el judicial y demostrativo, la descriptio en el judicial y el demostrativo y el locus communis en el judicial.

\section{Los Ioannis Laurentii Palmyreni Scholia in Aphthonium}

El comentario de Palmireno es muy breve y, como señala en la carta al lector, consiste, principalmente, en remitir a autores ${ }^{14}$. Estos no son sólo clásicos, sino que también se encuentran entre ellos humanistas. En ocasiones, aparece un término o expresión de la versión de Cataneo que da lugar al comentario y, en otras, se comenta de manera general el ejercicio.

Aunque el autor alcañizano no menciona el comentario de Lorich ni la versión mixta de Cataneo y Agrícola que lo acompaña, su deuda con el alemán es evidente, como veremos al examinar el comentario.

Los scholia de Palmireno a la Fabula se centran en su origen, su uso por oradores y filósofos y su tratamiento abreviado y dilatado. El comentario gira en torno a dos entradas: a poetis y Qua etiam oratores. En a poetis remite a la Suda, donde se muestra que Hesíodo es ciento tres años más antiguo que Esopo, y a Quintiliano, libro 5, capítulo 11. En Qua etiam oratores remite a Menenio Agripa (LIV.2.32-33); a la fábula de la sombra del asno de Demóstenes ${ }^{15}$; y a la que cuenta Herodes Ático según la recoge Gelio en Noctes Atticae 19.12. Continúa señalando que también la utilizan los filósofos y ofrece como ejemplos Macrobio, capítulo 2 del libro 1, en el Sueño de Escipión; Platón, en el libro segundo de la República ${ }^{16}$; y Cicerón en el libro 3 del De officiis (3.38), en el que se recoge la del anillo de Giges.

Sobre el tratamiento de la fábula ampliada y abreviada remite a Prisciano y como ejemplos de fábula indica el adagio de Erasmo Scarabeus aquilam quaerit (Adagia 7:2601); el del cuervo y la zorra de Apuleyo (De deo Socratis, praef.4); el ratón de ciudad en Horacio (sat.79-117); De Cassita en Aulo Gelio, 2,29; la fábula del ruiseñor y el gavilán, que la trató Hesíodo en los Trabajos y los Días (202-214). La fábula se puede dilatar con estos capítulos: alabanza del autor; la moraleja; la naturaleza del gavilán; sermocinatio, prosopopeya; comparación, contrario y, finalmente,

14 Nos igitur quoniam scholiaste personam suscepimus, laconica breuitate rem ipsam persequemur. Sat enim erit digito fontem quaerere uolentibus indicasse (f. 23r-v)

15 Plutarco se lo atribuye a Demóstenes en las Vidas de los diez oradores 848a-b.

16 En el libro segundo de la República, Platón incluye la fábula del anillo de Giges (359d-360b). 
la conclusión. Todas estas referencias, excepto la del cuervo y la zorra de Apuleyo y el adagio de Erasmo, se encuentran en el comentario de Lorich.

En los scholia a la Narratio no hay entradas y el interés de Palmireno está centrado en los tipos de narración y en proporcionar ejemplos. Sobre los tipos de narración, para el remoto remite a Aftonio, para los demás a Trebizonda ${ }^{17}$. Como ejemplos de narración fabulosa señala la de Píramo y Tisbe que se encuentra en las Metamorfosis de Ovidio (met.4.55-166); para la histórica, la de Ciro, en Orosio libro 2, capítulo 8; para la civil, el Pro Milone de Cicerón, desde P. Clodius cum statuisset hasta in tali re facere uoluisset (Mil.24); y el discurso de Pompeyo desde adque ut inde mea proficiscatur oratio hasta ab hostibus metui praeterea neminem (Manil.4-5). Toda la información que proporciona Palmireno en este ejercicio aparece también en Lorich.

En cuanto a la Chria, Palmireno afirma que, al llegar a este ejercicio, los jóvenes se desmoralizan y se preguntan de dónde podrán extraer los ejemplos y el testimonio de los antiguos. El humanista ofrece un repertorio de fuentes de las que se pueden obtener. Se hallan ejemplos en las Parabolae de Erasmo, en autores como Valerio Máximo, Ravisio Téxtor y Baptista Fulgoso, así como en los Exempla uirtutum et uitiorum. En cuanto a los testimonios de los antiguos, se pueden encontrar en la $\mathrm{Po}$ lyanthea de Nano Mirabelio, en los Flores poetarum de Octaviano Mirandola y en los Adagia de Erasmo.

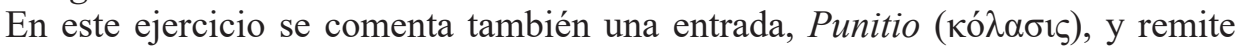
erróneamente a Aulo Gelio 6.14 (en realidad se encuentra en 7.14). También señala que hay ejemplos muy elegantes de chria en Estéfano Niger; en el capítulo 27 del libro 26 de los Antiquarum Lectionum libri de Celio Rodigino y en el exordio del De Officiis de Cicerón. Tanto la entrada de Punitio como la referencia a Estéfano están en Lorich.

El comentario a la Sententia se limita a indicar que hay ejemplos elegantes en Prisciano y en Estobeo. La mención a Prisciano se halla en Lorich.

En el progymnasma de la Confutatio el alcañizano recomienda leer a Quintiliano, libro 2, capítulo 4; y libro 5, capítulo 3; y añade que un buen ejemplo es la refutación de Marco Porcio Catón en Tito Livio acerca de las Bacanales. Nuevamente, encontramos en Lorich la referencia a Quintiliano y entre sus ejemplos incluye el de las Bacanales que atribuye a Catón. Palmireno ha tomado de Lorich la errónea asignación a Catón de este discurso que recoge Livio (39.15-16) y que fue pronunciado por el cónsul Espurio Postumio Albino; Catón pronunció el discurso contra la derogación de la Ley Opia que se encuentra también en Livio (34.1-4).

El comentario a la Confirmatio consiste solo en una cuestión de traducción referida a la entrada quisquis uituperat que también comenta Lorich. Palmireno indica que, ya que hay tanta variedad de traducciones del texto griego, él ofrece la suya literal (ad uerbum): poetis contradicens ipsis contradicere uidetur musis.

Palmireno sigue a Lorich como fuente de su comentario al Locus communis. Comienza sus scholia indicando que a este ejercicio lo llaman forma rerum y que son loci communes la fortuna, las riquezas, la pobreza y sus contrarios. Luego, remite a la epístola de Agrícola en De ratione studiorum y a la Copia de Erasmo. Señala que lo utilizan acusadores y defensores porque o acentúa lo atroz del delito o lo atenúa y atrae la misericordia. Recomienda como fuentes para la teoría el libro tercero de la

17 Trebizonda trata de los narrationum genera en el libro I de los Rhetoricorum libri $V$. 
Rhetorica ad Herennium y el libro segundo de la Retórica de Trebizonda. A continuación, añade que se va más allá de la persona, pues se atacan los vicios, para lo que remite a inst.2.4. Afirma que se les llama comunes porque se pueden aplicar a todos lo que comparten el mismo vicio como señala Trebizonda; según Aftonio es una amplificación porque con él se acrecientan los delitos y las virtudes; sobre este tema, recomienda de nuevo el libro segundo del tratado ad Herennium y el capítulo catorce del libro segundo de Agrícola. Seguidamente señala los tópicos de argumentación del lugar común que toma del contra ebrium, uno de los ejemplos de locus commnunis de Lorich: exordio, a contrario, ab expositione, a comparatione, a sententia, a uita antecedente, a misericordia exclusione, a legitimo, honesto ${ }^{18}$, utili, possibili, euenturum (que no aparece en Lorich) y epilogus. En el tópico de argumentación sententia remite, como Lorich, a la Epistola 12 de Seneca: ebrietas uoluntaria insania. Sin embargo, hay un error en la cita de Palmireno, porque el texto se encuentra en Ad Lucilium 83.18. Termina el comentario con la afirmación de que el mismo argumento lo trata con mucha elegancia Pedro Moselano e indica que un ejemplo contra el sacrílego lo ofrece Prisciano. Ambos ejemplos se encuentran en Lorich.

Para la Laus, el humanista alcañizano remite a los ejemplos que se encuentran en el De inventione oratoria de Bulcodiano (De inventione et amplificatione oratoria seu usu locorum libri III). Entre los ejemplos que utiliza Lorich hay algunos de Bulcodiano.

No hay en Palmireno escolios a la Vituperatio.

Como ejemplos de Comparatio Palmireno ofrece los de Plutarco: Solón/Publícola, Alcibiades/Coriolano y Pericles/Fabio. Estas referencias se encuentran también en Lorich.

Para la Ethopoeia, al igual que Lorich, recomienda leer el capítulo segundo del libro 9 de Quintiliano (9.2.58) y también como él señala que hay ejemplos de Libanio traducidos por Erasmo ${ }^{19}$, como las palabras de Andrómaca y las de Medea. Finalmente, señala que en Plutarco pueden verse ejemplos de etopeya, como el de Cornelia en la vida de Pompeyo y el de Cleopatra en la vida de Antonio.

Respecto a la Descriptio, Palmireno afirma que la explican con mucha elegancia Vives en su Rhetorica y Erasmo en el libro segundo de la Copia. Para ejemplos de este ejercicio, remite a Erasmo que nos mostrará dónde pueden encontrarse. Señala que también puede leerse la vida de Hilarión escrita por Jerónimo en la que se describe la habitación de San Antonio. Por último, indica que Lucano en el libro noveno describe serpientes (9.700-733). En el comentario de Lorich se mencionan las referencias a Erasmo y a Lucano.

Los escolios a la Thesis y a la Legislatio son muy breves y se limitan a remitir a varios autores; en la Thesis, a Quintiliano, al capítulo 5 del libro 3 (3.5.4) y al libro 2, capítulo1 (2.1.9), así como al De conscribendis epistolis de Erasmo. En la Legislatio remite al libro 2, capítulo 4 de Quintiliano (2.4.33-40). Todas estas referencias a Quintiliano las encontramos también en Lorich.

18 Falta en Palmireno el tópico de argumentación iusto, que sí está en Lorich, aunque tratado conjuntamente con honesto, utili, posibili.

19 Libanii Sophistae Graeci declamatiunculae aliquot, eaedemque Latinae per Des. Erasmum Rot. In Inclyta Basilea ex aedibus Io. Frob. Mense Martio. Anno MDXXII. 


\section{Quomodo status cognoscemus secundum Hermogenem}

A continuación de los Scholia de Palmireno se encuentra un resumen sobre el reconocimiento de los status a partir de Hermógenes titulado Quomodo status cognoscemus secundum Hermogenem. En él se ofrece, en primer lugar, una breve definición de los status cuyo nombre aparece en los márgenes. Se definen coniecturalis, finitio, absoluta o antilepsis, comparatio, recriminatio, translatio criminis, deprecatio, negotialis, scriptum et sententia, contrariae leges, ratiocinatio, amphibologia, remotio criminis o metalepsis. Seguidamente se señala lo que es propio de la coniectura, definitio, antilepsis, antistasis, anticlimax, deprecatio, negotialis, recriminatio, antinomia, amphilogia y metalepsis. Este apartado finaliza, como ya hemos dicho, con la atribución de los progymnasmata a los tria genera. Este resumen no es de Palmireno, sino que está tomado literalmente del que aparece en el volumen de la traducción de la obra hermogénica realizada por Antonio Bonfini y publicada en Lyon en $1538^{20}$.

\section{Carta de Antoni Sanahuja al estudioso}

El libro concluye con una carta del librero Antoni Sanahuja al estudioso fechada en Valencia el 1 de octubre de 1552. En ella afirma, refiriéndose al apartado Quomodo Status cognoscemus secundum Hermogenem, que esto es lo que dejó escrito Hermógenes acerca de los status y que no debe sorprender su dilucida brevedad, sino que debe ser elogiada porque arroja luz sobre un tema tan difícil que trataron Cicerón y Quintiliano en extensos volúmenes, pues contiene todo lo necesario que hay saber sobre este asunto sin necesidad de acudir a otros escritos. Por otro lado, advierte al estudioso que, en su versión, Cataneo no ha seguido al pie de la letra (ad ungem) el códice griego, sino que en algunas lecturas lo ha respetado y en otras no.

\section{Conclusiones}

La principal aportación de este trabajo es la recuperación de los Aphthonii clarissimi rhetoris Progymnasmata Ioanne Maria Catanaeo interprete de Juan Lorenzo Palmireno, publicados en Valencia en 1552, en las prensas de Joan Mey, obra de la que solo teníamos referencias a través de otros autores.

Del estudio de la obra podemos concluir que, a pesar de que Palmireno afirma en su carta dedicatoria a Jerónima que ha aportado meum quibusdam iudicium en la versión que ofrece, esta es la de Cataneo que Froben publica en 1521 con escasas variantes. Por otro lado, en lo que se refiere al breve resumen de los status de Hermógenes es una reproducción literal del que aparece en el volumen de la traducción de la obra del rétor griego realizada por Antonio Bonfini y publicada en Lyon en 1538, aunque Palmireno no lo mencione.

Los Scholiola son muy breves y se limitan a remitir a autores clásicos y humanistas como apoyo a la teoría y como fuente de ejemplos para los ejercicios con una

20 Hermogenis Tarsensis Philosophi ac Rhetoris acutissimi De arte rhetorica praecepta... Antonio Bonfine interprete. Lugduni, apud Seb. Gryphium, 1538, 381-383. 
gran influencia de Lorich, aunque no lo mencione. En cuanto a los autores citados por Palmireno, encontramos tanto autores clásicos como humanistas y en una sola ocasión a un padre de la Iglesia (Jerónimo). Para la teoría remite a: la Rhetorica ad Herennium, Cicerón, Quintiliano, Prisciano, Trebizonda, Agrícola, Erasmo y Vives; para los ejemplos, a: Cicerón, Lucano, Livio, Plutarco, Séneca, Plinio, Aulo Gelio, Valerio Máximo, Prisciano, Libanio, Jerónimo, Mirabelio, Mirandola, a Fulgoso, a Moselano, a Estobeo, a Erasmo, a Bulcodiano, a Textor, a Rodigino, Estéfano Niger y los Exempla uirtutum et uitiorum.

Por otro lado, de las cartas incluidas en el libro, debemos destacar especialmente que, en la que cierra el libro, el librero Antoni Sanahuja solo menciona el resumen de los status de Hermógenes y la versión de Cataneo, mientras que omite cualquier referencia a los Scholia de Palmireno.

La recuperación del ejemplar de los Aphthonii clarissimi rhetoris Progymnasmata Ioanne Maria Catanaeo interprete de Palmireno permite avanzar en el conocimiento del humanismo español de mitad del siglo XVI y especialmente del foco valenciano, así como mostrar la vinculación de los humanistas españoles con las grandes corrientes del humanismo europeo y cómo se sirven de los mismos autores y manuales que se utilizan en toda Europa en esta época.

\section{Referencias bibliográficas}

\section{Fuentes:}

Bonfinius, Antonius (1538), Hermogenis Tarsensis Philosophi ac Rhetoris acutissimi De arte rhetorica praecepta. Aphthonii item Sophistae Praexercitamenta, Antonio Bonfine interprete, Lugduni, apud Seb. Gryphium.

Palmirenus, Ioannes Laurentius (1552), Aphthonii clarissimi rhetoris Progymnasmata Ioanne Maria Catanaeo interprete, nunc denuo recognita iuxta ueritatem Graeci exemplaris \& scholijs illustrata per Ioannem Laurentium Palmyrenum Alcanizensem ludimagistrum Valentinum D. Hieronymae Ribotae dicata. Accessit etiam ex Hermogenis sententia, quo modo status causae cognosci debeat, Valentiae, ex officina Ioannis Mey Flandri, prostant exemplaria apud Antonium Sanahuiam, sub scuto Beatae Mariae \& D. Antonij.

Palmireno, Juan Lorenzo (1573a), Razonamiento que hizo Palmyreno a los regidores de su patria de la orden de enseñar, en Segunda parte del latino de repente, Valencia, Pedro Huete.

Palmireno, Juan Lorenzo (1573b), El estudioso cortesano, Valencia, Pedro Huete.

Lorichius, Reinhardus (1542), Aphthonii Progymnasmata partim a Rodolpho Agricola partim a Joanne Maria Catanaeo latinitate quondam donata, iam recens longe tertius edita, simul ac Scholiis luculentis, nouisque compluribus exemplis illustrata, per Reinhardum Lorichium Hadamarium, Marpurgi, in officina Christiani Egenolphi.

Veterum aliquot De arte rhetorica traditiones de tropis in primis et schematis uerborum et sententiarum non aspernanda me Hercle opuscula, nunc primum in lucem edita, cum quibusdam aliis, quorum ordo sequenti pagella describitur, Basileae, in aedibus Ioannis Frobenii, 1521. 


\section{Monografías y artículos}

Anyés, J. B. (2001), Obra profana. Apologies, València 1545. Introducción de E. Durán y edición y traducción al catalán de M. Durán y Mateu, Barcelona - Madrid, Real Acadèmia des Bones Lletres - UNED.

Arcos Pereira, T. - Cuyás de Torres, MªE. (2014), «Las traducciones de los Progymnasmata de Aftonio: estudio preliminar de la versión partim Agricola, partim Catanaeo y de la realizada por J. Camerario», en Baños Baños, J.M., Barrio Vega, MF del, Callejas Berdonés, Mª, López Fonseca, A. (eds.), Philologia,Universitas, Vita.Trabajos en honor de Tomás González Rolán, Madrid, Escolar y Mayo Editores, 93-102

Bonmatí Sánchez, V. (2006), Humanistas europeos (siglos XIV - XVI), Madrid, Editorial Complutense.

Carabias Torres, A.M (1983), El Colegio Mayor de Cuenca en el siglo XVI: Estudio Institucional. Salamanca, Ediciones Universidad de Salamanca.

Cea Galán, Maj. (2009), Juan Lorenzo Palmireno. Discursos latinos. Introducción, edición crítica, traducción anotada e índices a cargo de María José Cea Galán, Alcañiz - Madrid, Instituto de Estudios Humanísticos-CSIC.

Clark, D.L. (1952), «The Rise and Fall of Progymnasmata in Sixteenth and Seventeenth Century Grammar Schools», Speech Monographs 19 (4), 259-263.

Cuyás de Torres, $M^{\mathrm{a}} \mathrm{E}$. (2014), «Aftonio en el Renacimiento: el comentario al lugar comun de Lorich», Humanistica Lovaniensia, 153-177.

Díaz y Díaz, G. (2003): Hombres y documentos de la Filosofía española, vol. VII, Madrid, Consejo Superior de Investigaciones Científicas.

Durán, M. (2002), «El conocimiento del griego por parte de Joan Baptista Anyés», en Maestre Maestre, J.M , Pascual Barea, J., Charlo Brea, L. (eds.), Humanismo y Pervivencia del Mundo Clásico. Homenaje al profesor Antonio Fontán, Alcañiz - Madrid, Instituto de Estudios Humanísticos-CSIC, 2449-2456.

Durán, M. (2003), «El Cercle literari d’Àngela Sabata», en Grau Codina, F., Gómez Font, X., Pérez Durà, J. y Estellés González, J.M (eds.), La Universitat de València i l'Humanisme: Studia humanitatis i renovació cultural a Europa i al Nou Món, Valencia, Universitát de València, 415-422.

Escolano, G. (1878-1880), Décadas de la historia de la insigne y coronada ciudad y Reino de Valencia por el licenciado Gaspar Escolano; aumentada y continuada hasta nuestros días por Juan B. Perales; obra ilustrada con profusión de grabados al cromo, Valentiae, impresión de Carlos Verdejo.

Gallego Barnés, A. (1982), Juan Lorenzo Palmireno (1524-1579): un humanista aragonés en el Studi general de Valencia, Zaragoza, Institución Fernando el Católico.

Gallego Barnés, A. (2002), «Discípulos aventajados de Juan Lorenzo Palmireno», en Maestre Maestre, J.Ma, Pascual Barea, J., Charlo Brea, L. (eds.), Humanismo y Pervivencia del Mundo Clásico. Homenaje al Profesor Antonio Fontán, Alcañiz-Madrid, Instituto de Estudios Humanísticos - CSIC - Laberinto, vol. III.1: 161-175.

Garés Timor, V.M. (2013), «Conflictividad social y violencia de género en la nobleza valenciana del siglo XVI. El intento fracasado de unión de los señoríos de Carlet y l'Alcúdia», en Serrano Martín, E. (coord.), De la tierra al cielo. Líneas recientes de investigación en Historia Moderna. I encuentro de jóvenes investigadores en Historia Moderna, Zaragoza, Institución Fernando el Católico.

Green, L.D. - Murphy, J.J. (2006), Renaissance Rhetoric. Short-Title Catalogue 1460-1700, Aldershot, Ashgate Publishing Company. 
Johnson, F.R. (1942-43), «Two Renaissance Textbooks of Rhetoric: Aphthonius’ Progymnasmata and Rainolde's A booke called the Foundacion of Rhetorike», Huntington Library Quarterly 6, 436-437.

Luján Atienza, A.L. (1997), Contribución al estudio de las retóricas españolas del siglo XVI: el foco de Valencia, Tesis doctoral presentada en la Facultad de Filología de la Universidad Complutense de Madrid.

Maestre Maestre, J.Mª (1990), El humanismo alcañizano del siglo XVI. Textos y estudios de latín renacentista, Cádiz.

Margolin, J.Cl. (1979), «La Rhetorique d'Aphthonius et son influence au XVIe siècle», en Chevalier, R. (ed.), Colloque sur la Rhetorique. Calliope I, París, 239-269.

Moll, J. (2011), «Antoni Sanahuja, librero, editor e impresor valenciano», en Problemas bibliográficos del libro del Siglo de Oro, Madrid, Arco Libros (Colección Instrumenta Bibliológica), 167-173.

Pérez Custodio, V. (2002), «Sobre el origen de los materiales contenidos en los Progymnasmata de Palmireno», en Maestre Maestre, J.Ma, Pascual Barea, J., Charlo Brea, L. (eds.), Humanismo y Pervivencia del Mundo Clásico. Homenaje al Profesor Antonio Fontán, Alcañiz-Madrid, Instituto de Estudios Humanísticos - CSIC - Laberinto, vol. III.1, 245259.

Pérez Custodio, V. (2003), Alfonso de Torres. Ejercicios de Retórica. Introducción, edición crítica, traducción anotada e índices, Alcañiz - Madrid, Instituto de Estudios Humanísticos-CSIC.

Vallés Borràs, V. (2002), De la Carta de Poblament a l'ocàs de l'antic règim (1252-1800), L'Alcúdia, Ayuntamiento de L'Alcúdia.

Vega y de Luque, C.L. de la (1973), «Vida y obra de Juan Lorenzo Palmireno», Teruel 49-50, 111-186. 